\title{
PEMBERDAYAAN WANITA TANI DALAM USAHA PRODUKSI ABUCA (ABON DAN BUBUK CABAI) DI KECAMATAN ADILUWIH KABUPATEN PRINGSEWU
}

\author{
Dwi Dian Novita*, Winda Rahmawati \\ Jurusan Teknik Pertanian FP Universitas Lampung \\ Jl. Prof. Sumantri Brojonegoro No.1 Bandar Lampung 35145 \\ Penulis Korespodensi : dwi.diannovita@fp.unila.ac.id
}

\begin{abstract}
Abstrak
Teknologi pengolahan abon dan bubuk cabai (Abuca) tergolong cukup mudah sehingga dapat diterapkan oleh para istri petani yang tergabung dalam Kelompok Wanita Tani (KWT) "Maju” di Desa Waringinsari Timur, Kecamatan Adiluwih, Kabupaten Pringsewu. Pemberdayaan KWT dalam usaha produksi Abuca menjadi salah satu solusi bagi permasalahan harga jual cabai yang sangat rendah pada saat panen raya. Rangkaian kegiatan PKM ini terdiri dari: (1) sosialisasi dan koordinasi, (2) penyuluhan pascapanen dan peluang usaha pengolahan cabai, (3) penentuan merk dan desain label kemasan (4) praktik produksi Abuca dan pemasaran produk, serta (5) evaluasi kegiatan. Transfer pengetahuan dan alih teknologi kepada mitra dilakukan dengan metode pelatihan dan praktik. Setelah dibina selama 4 bulan (Juli-Oktober 2019), para anggota KWT Maju kini telah memiliki pengetahuan dan keterempilan untuk memproduksi Abuca dan telah memiliki produk dengan merk "Hot Asoy". Terdapat 3 varian abon cabai yang diproduksi yaitu rasa teri, rebon, dan original (rasa bawang). Abon cabai dikemas per 50 gram dalam botol dan standing pouch plastik dengan harga jual Rp.18.000,- dan Rp.15.000,-. Sedangkan bubuk cabai dikemas per 100 gram dalam standing pouch plastik dengan harga jual Rp.10.000,-.
\end{abstract}

Kata kunci: abuca, abon cabai, bubuk cabai, KWT

\section{Pendahuluan}

Cabai merah (Capsicum annum, L) merupakan bahan pangan yang baik bagi tubuh manusia karena mengandung zat antioksidan yang berfungsi sebagai penangkal radikal bebas. Cabai juga mengandung senyawa lasparaginase dan capsaicin yang berperan sebagai zat anti kanker (Setiadi, 1999). Kandungan senyawa capsaisin membuat cabai memiliki cita rasa pedas yang disukai oleh sebagian besar masyarakat Indonesia. Selain bermanfaat bagi kesehatan, rasa pedas juga berkasiat sebagai penambah nafsu makan.

Tanaman cabai merah mudah tumbuh di dataran rendah maupun di dataran tinggi. Salah satu daerah yang para petaninya giat membudidayakan tanaman ini adalah di Desa Waringinsari Timur yang terletak di Kecamatan Adiluwih, Kabupaten Pringsewu. Total luas lahan yang digunakan untuk bertanam cabai di desa ini mencapai 8 hektar yang diusahakan oleh sekitar 25 orang petani dengan produktivitas mencapai 10 ton/hektar.

Vol 4 No 2 Juli 2020
Seperti halnya di sentra penghasil cabai lainnya, para petani di Desa Waringinsari Timur juga dihadapkan pada permasalahan harga disaat panen raya. Pada kondisi panen awal, harga cabai tergolong baik yaitu berkisar Rp.19.000,-/kg di tingkat petani. Namun harga cabai ini terus mengalami penurunan hingga mencapai nilai terendah saat panen raya yaitu pada kisaran harga Rp.5000,-/kg. Dengan harga jual di bawah Rp.10.000,-/kg dapat dipastikan petani mengalami kerugian besar karena hasil penjualan tidak cukup untuk mengganti biaya produksi yang telah dikeluarkan. Namun walaupun harga sangat rendah, para petani terpaksa tetap menjual hasil panen karena mereka tidak memiliki pilihan lain. Mereka belum memiliki pengetahuan dan teknologi untuk mempertahankan kesegaran cabai atau upaya pengolahan untuk memperpanjang umur simpan cabai.

Cabai merupakan salah satu produk pertanian yang mempunyai kadar air lebih dari 90\% sehingga termasuk dalam golongan produk yang sangat mudah rusak (high perishable) 
(Sujatha dan Wisaniyasa, 2007). Untuk itu harus diupayakan alternatif lain untuk mengatasi sifat cabai yang sangat mudah rusak dan jatuhnya harga cabai. Salah satunya dengan penerapan teknologi pasca panen untuk mengolah cabai menjadi produk memiliki nilai jual yang tinggi dan umur simpan yang lama.

Teknologi pengolahan Abuca tergolong cukup mudah sehingga dapat diterapkan oleh para istri petani cabai yang tergabung dalam Kelompok Wanita Tani (KWT) "Maju". KWT ini telah terbentuk sejak tahun 2013 lalu namun kegiatannya baru terbatas pada kegiatan sosial kemasyarakatan. Proses pengolahan bubuk cabai terdiri dari tahapan sortasi, pencucian, blansir, penirisan, pengeringan dan penggilingan. Sedangkan abon cabai merupakan produk turunan dari bubuk cabai. Secara sederhana proses pengolahannya adalah mencampurkan bubuk cabai dengan bubuk teri, rebon atau bawang dan dibumbui dengan gula dan garam (Dirjen PPHP, 2009).

Pemberdayaan wanita tani dalam usaha produksi Abuca dapat menjadi salah satu solusi untuk mengurangi kerugian para petani disaat panen raya dimana harga cabai segar menjadi sangat rendah. Kegiatan ini sekaligus menjadi aktifitas ekonomi untuk menunjang kesejahteraan KWT.

\section{Bahan, Peralatan dan Metode}

\section{A. Bahan dan Peralatan}

Bahan-bahan yang digunakan adalah cabai merah besar, cabai rawit caplak, teri, rebon, bawang putih, bawang merah, minyak goreng, gula, garam, dan penyedap rasa.

Peralatan utama yang digunakan yaitu blender, oven, loyang, wajan, kompor, baskom, nampan, pisau, sarung tangan, masker, celemek, botol dan standing pouch plastik kemasan, serta peralatan pendukung produksi lainnya.

\section{B. Metode}

Kegiatan Pengabdian kepada Masyarakat (PKM) Skema Unggulan Unila ini dilaksanakan di Desa Waringinsari Timur Kecamatan Adiluwih Kabupaten Pringsewu, selama 4 bulan yaitu pada Bulan Juli hingga Oktober 2019. Mitra kegiatan ini adalah Kelompok Wanita Tani (KWT) Maju yang diketui oleh Ibu Siti Munawaroh. Kegiatan ini juga melibatkan PPL Pertanian setempat yaitu Ibu Nani Lestari, S.P.
Rangkaian kegiatan PKM ini terdiri dari: (1) sosialisasi dan koordinasi, (2) penyuluhan pascapanen dan peluang usaha pengolahan cabai, (3) penentuan merk dan desain label kemasan (4) praktik produksi Abuca dan pemasaran produk, serta (5) evaluasi kegiatan.

\section{Hasil dan Pembahasan}

\section{A. Koordinasi dan sosialisasi program kepada mitra}

Koordinasi dan sosialisasi kepada KWT Maju dan PPL Pertanian dilaksanakan pada tanggal 27 Juli 2018. Koordinasi juga dilakukan dengan Kepala UPT Pertanian Kecamatan Adiluwih. Kegiatan ini bertujuan untuk menyampaikan gambaran dan tujuan program, serta target yang ingin dicapai dari kegiatan PKM ini. Selain itu, koordinasi juga bertujuan untuk menampung ide dan saran dari mitra dan pihak-pihak terkait. Kegiatan ini berlangsung dengan lancar, KWT Maju menyatakan kesediaan dan komitmennya untuk berperan aktif dalam kegiatan ini. Dukungan juga didapatkan dari PPL dan KUPT setempat.

\section{B. Penyuluhan pascapanen dan peluang usaha pengolahan cabai}

Penyuluhan pascapanen cabai dilakukan pada tanggal 24 Agustus 2019. Materi pascapanen ini menjadi bekal bagi KWT untuk menangani hasil panen cabai agar terjaga kualitasnya hingga sampai ke pasar atau ke tangan konsumen. Penanganan pascapanen yang tepat akan memperpanjang umur simpan komoditi dan mengurangi losses. Selain itu juga diberikan pengetahuan tentang manfaat pengeringan sebagai cara untuk mengawetkan cabai terutama saat musim panen raya tiba. Cabai kering merupakan produk antara (intermediet) yang memiliki umur simpan lebih lama dan dapat dimanfaatkan langsung sebagai bumbu masakan atau menjadi bahan baku olahan abon dan bubuk cabai (Abuca).

Kepada para peserta penyuluhan juga disampaikan profil usaha abon dan bubuk cabai yang telah ada di pasaran diantaranya Merk Bon Cabai, Ninoy, Peucun, dan Evia. Merk-merk tersebut telah cukup dikenal dan memiliki pangsa pasar lokal. Teknologi pengolahan Abuca yang sederhana dan ketersedian cabai yang stabil bahkan melimpah saat panen raya di daerah Adiluwih, merupakan alasan kuat bagi KWT Maju untuk memilih usaha produksi Abuca sebagai kegiatan ekonomi kelompok. 

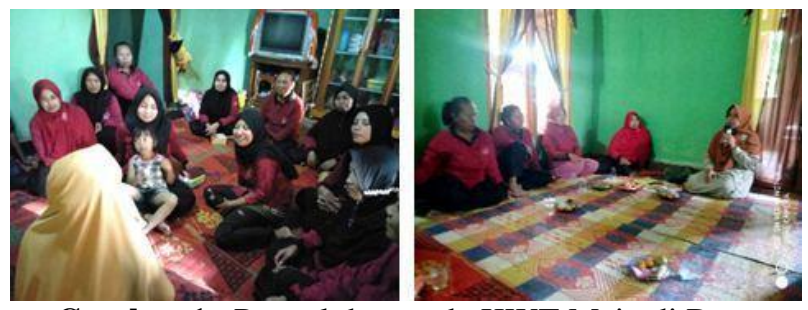

Gambar 1. Penyuluhan pada KWT Maju di Desa Waringinsari Timur Kec. Adiluwih

Setelah dilakukan penyuluhan, KWT Maju diminta melakukan praktik pengeringan cabai. Pada awalnya, KWT menjemur cabai utuh di bawah sinar matahari menggunakan tampah yang terbuat dari ayaman bambu. Berdasaran evaluasi, proses pengeringan ini memerlukan waktu yang cukup lama yaitu sekitar 6 hari. Untuk mempercepat proses pengeringan, Tim Pelaksana menyarankan kepada KWT untuk memotongmotong cabai terlebih dahulu sebelum dijemur dan mengganti tampah bambu dengan loyang-loyang stainless berukuran besar sebagai alas jemur.

Cara ini dipraktikkan pada proses pengeringan cabai berikutnya. Penjemuran dilakukan dengan menempatkan cabai di atas loyang-loyang stainless. Selanjutnya diletakkan di atas bangku penyangga (Gambar 2). Hal ini dilakukan agar kebersihan cabai terjaga, menghindari kontaminasi dan gangguan dari hewan ternak. Selain itu, teknik ini membuat udara mengalir lancar di sekitar bahan. Aliran udara panas akan membawa uap air dari dalam cabai. Hasilnya, pengeringan berlangsung lebih singkat yaitu hanya 4 hari dengan kondisi cuaca yang relatif sama.
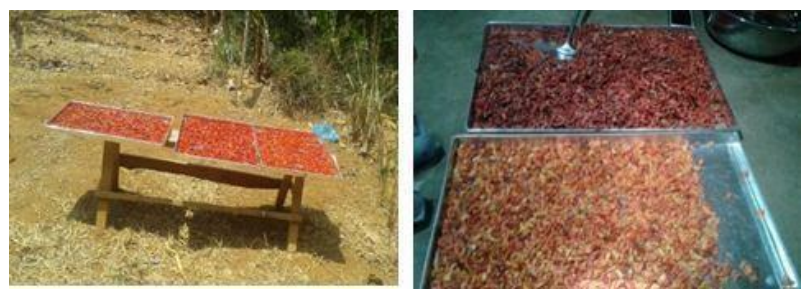

Gambar 2. Penjemuran cabai oleh KWT Maju di Desa Waringinsari Timur

\section{Penentuan merk dan desain label kemasan produk}

Produk abon dan bubuk cabai yang diproduksi oleh KWT Maju diberi merk "Hot Asoy". Merk ini merupakan usulan dari kelompok yang dinilai sesuai dengan produk. Merk "Hot Asoy" bermakna "Pedas Enak" atau "Pedas Mantab" sesuai dengan citarasa pedas mantab dengan 3 pilihan rasa yang enak.

Label produk abon cabai "Hot Asoy" didominasi warna merah tepatnya merahkekuningan sedangkan untuk bubuk cabai bernuansa kuning-kecoklatan. Informasi pada label meliputi (1) nama produk \& logo, (2) deskripsi produk, (3) komposisi, (4) info variasi rasa, (5) label halal, (6) info produsen, (7) netto, (8) expired date, dan (9) No.PIRT (Gambar 3).

Kemasan yang baik memiliki ciri-ciri: (1) mampu mempertahankan kebersihan produk, (2) melindungi produk dari kerusakan fisik, air, dan oksigen, (3) efisien dan ekonomis dalam proses pengepakan, dan (4) memberikan informasi produk (Buckle, 1987). Selain itu, kemasan yang baik berperan sebagai sarana promosi untuk menarik konsumen. Wahana komunikasi antara produsen dan konsumen tentang produk yang ada dalam kemasan tersebut. Kemasan seyogyanya dapat mempengaruhi konsumen untuk membeli produk tersebut (Cenadi, 2000).

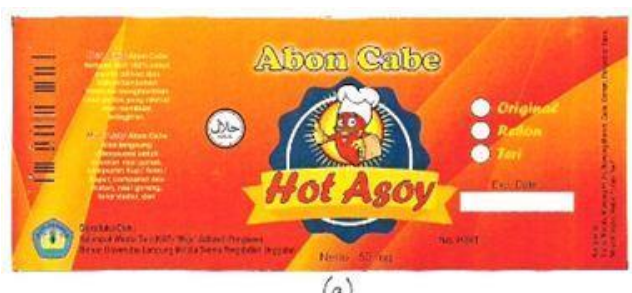

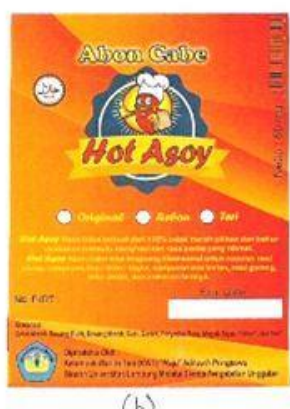

(b)

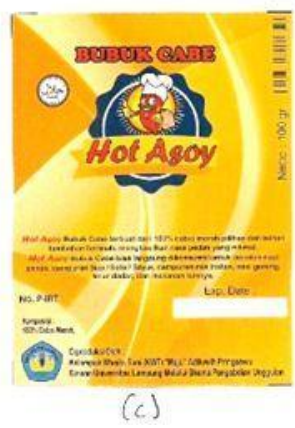

Gambar 3. Label Abuca "Hot Asoy". Abon cabai (a) kemasan botol, (b) kemasan standing pouch, (c) bubuk cabai.

\section{Praktik produksi Abuca dan pemasaran produk \\ Sejak Bulan Agustus 2019, Tim Pelaksana} telah melakukan ujicoba berbagai resep pembuatan abon dan bubuk cabai (Abuca) dari berbagai sumber hingga diperoleh resep yang menjadi acuan bagi mitra KWT. Pada tanggal 14 September dan 
5 Oktober 2019, Tim melatih anggota KWT Maju dalam praktik pembuatan Abuca dan memberikan bantuan peralatan produksi yang terdiri dari 1 unit oven ukuran besar, blender, kompor, wajan dan peralatan pendukung produksi lainnya (Gambar 4).

Target dari kegiatan praktik yang pertama pada tanggal 14 September 2019 adalah memberikan pengetahuan dan keterampilan kepada KWT untuk mengolah cabai kering menjadi Abuca. Para anggota KWT terlibat aktif dalam kegiatan ini dan berhasil membuat abon cabai dengan 3 varian rasa yaitu teri, rebon dan rasa bawang (original). Sedangkan bubuk cabai hanya ada 1 varian yang komposisinya terdiri dari $100 \%$ cabai asli.

Selanjutnya, para anggota KWT diminta untuk memperkenalkan dan memasarkan produk abon cabai kepada konsumen di lingkungan sekitar guna memperoleh saran dan masukan. Hasil evaluasi dari praktik produksi yang pertama ini adalah tentang citarasa. Penilaian konsumen menyatakan bahwa abon cabai yang dihasilkan masih memiliki level pedas "sedang" sementara sebagian besar konsumen merupakan penggemar cabai yang menyukai rasa sangat pedas. Hal ini menjadi acuan perbaikan pada praktik selanjutnya.

Pada praktik produksi kedua yang dilaksanakan pada tanggal 5 Oktober 2019 dilakukan koreksi resep berdasarkan saran dari para konsumen. Porsi cabai rawit caplak ditambah agar level pedas meningkat. Abon cabai yang diproduksi oleh KWT hanya memiliki satu level pedas yang diharapkan dapat memenuhi selera konsumen. Saat ini, KWT Maju telah memiliki resep abon cabai yang khas yang menjadi standar citarasa.

Hasil produksi kedua ini dikemas dalam botol isi 50 gram dan standing pouch plastik isi 100 gram masing-masing dipasarkan dengan harga Rp.18.000,- dan Rp.25.000,-. Sedangkan bubuk cabai dipasarkan dengan harga Rp.10.000,- /100 gram. Secara umum, abon cabai hasil produksi KWT mendapat respon positif dari konsumen. Namun masih banyak konsumen yang berharap harga produk bisa lebih murah. Upaya perbaikan yang dilakukan adalah mengadakan kemasan standing pouch plastik kecil berukuran 50 gram produk yang dapat dijual dengan harga lebih murah yaitu Rp.15.000,- (Gambar 4).
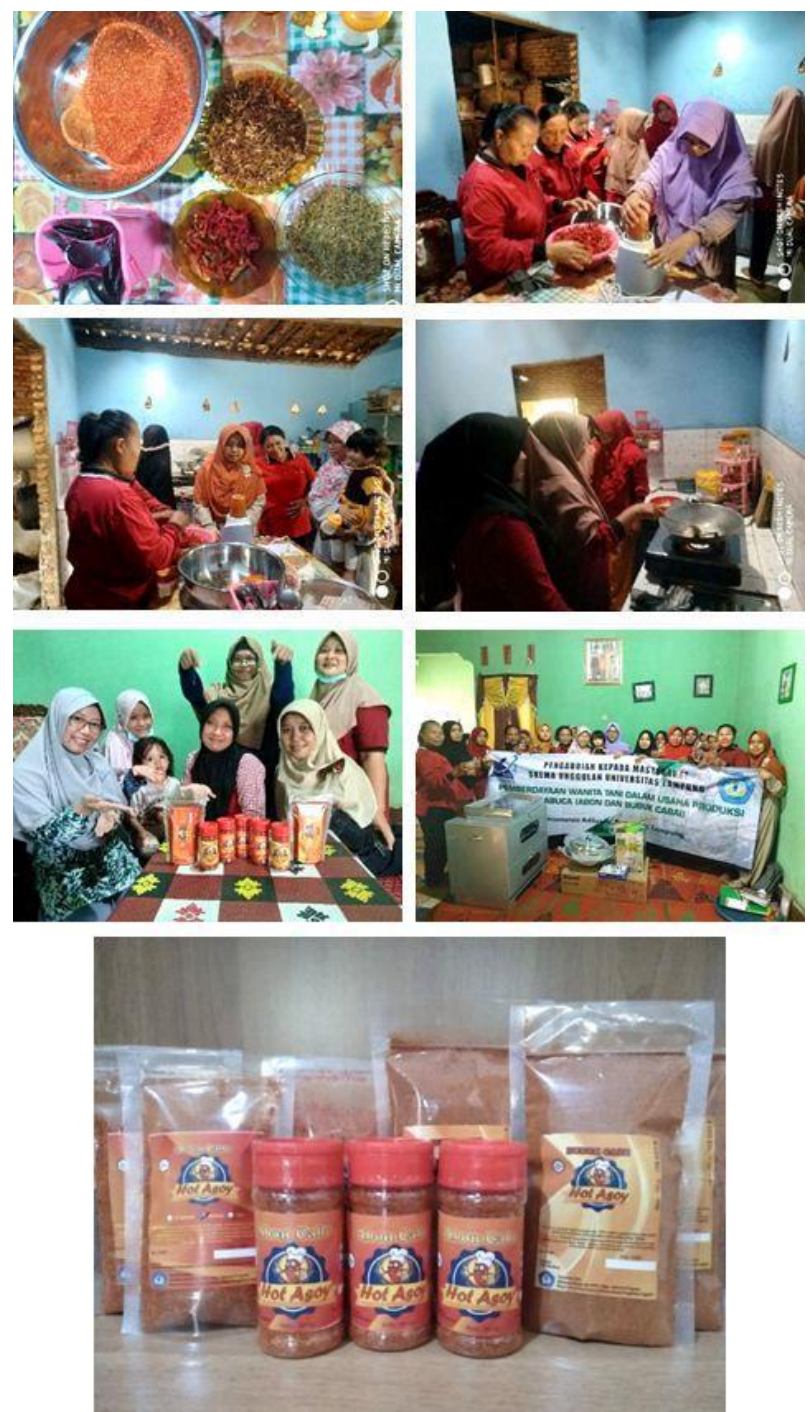

Gambar 4. Praktik produksi Abuca dan penyerahan peralatan pada KWT Maju di Desa Waringinsari Timur

Minat konsumen terhadap produk abon cabai lebih tinggi dibandingkan dengan bubuk cabai. Abon cabai dinilai lebih menarik dan citarasanya lebih enak. Penambahan teri, rebon dan bawang membuat abon cabai dapat langsung dikonsumsi bersama nasi putih dan dan hidangan lainnya. Abon cabai lebih serbaguna, bisa sebagai taburan bisa juga sebagai bumbu seperti untuk memasak nasi goreng dan aneka tumisan. Berdasarkan penilaian konsumen, citarasa abon cabai KWT Maju dapat bersaing dengan produk yang sudah ada dipasaran. Dari sisi keamanan pangan, abon cabai produksi KWT ini berbahan baku $100 \%$ cabai segar dan bahan-bahan pilihan. KWT juga mengutamakan kebersihan selama proses produksi sehingga produk sangat aman dan baik untuk dikonsumsi. 


\section{E. Evaluasi kegiatan}

Kegiatan evaluasi dilaksanakan pada tanggal 20 Oktober 2019. Peningkatan pengetahuan, keterampilan para anggota KWT Maju terlihat dengan sangat nyata. Sebelum dibina dalam kegiatan PKM ini, mereka belum memiliki ide untuk mengembangkan usaha produksi abon dan bubuk cabai. Mereka belum menguasai tekologi pascapanen \& pengolahan cabai, belum memiliki pengetahuan tentang pengemasan produk, serta belum memiliki peralatan produksi.

Setelah dibina selama 4 bulan (JuliOktober 2019) melalui serangkaian kegiatan, para anggota KWT Maju kini telah memiliki pengetahuan, keterempilan dan peralatan untuk membuat abon dan bubuk cabai dan telah memiliki produk dengan merk "Hot Asoy". Terdapat 3 varian abon cabai yang diproduksi oleh KWT yaitu rasa teri, rebon, dan dan original (rasa bawang). Abon cabai dikemas dalam botol dan standing pouch plastik dengan harga jual Rp.18.000,- dan Rp.15.000,-/50 gram produk. Sedangkan bubuk cabai dikemas dalam standing pouch plastik dengan harga jual Rp.10.000,- /100 gram produk.

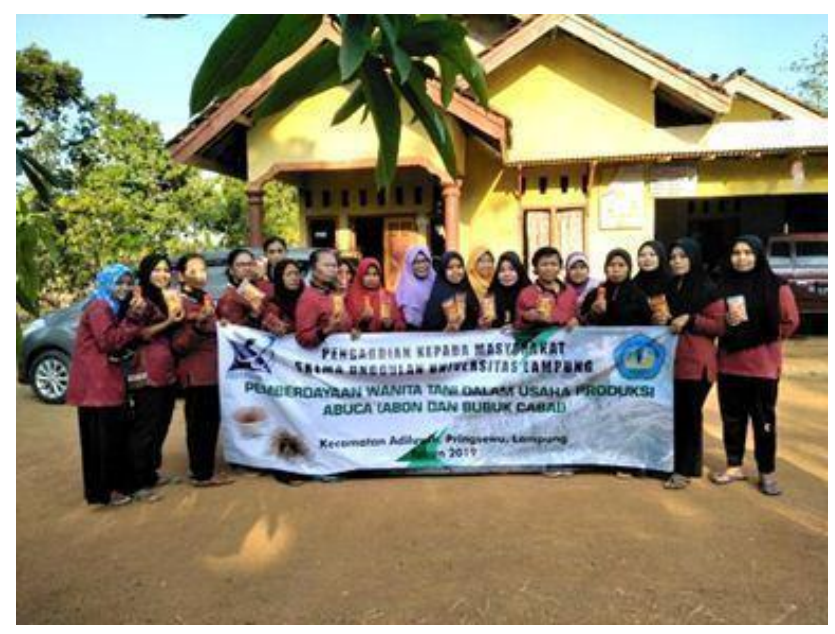

Gambar 5. KWT Maju dengan produk Abuca "Hot Asoy"

\section{Kesimpulan}

Kegiatan PKM pemberdayaan KWT Maju dalam usaha produksi abon dan bubuk cabai telah terlaksana dengan baik sesuai rencana. Anggota KWT Maju kini telah memiliki usaha produksi abon dan bubuk cabai dengan merk "Hot Asoy". KWT Maju memproduksi 3 varian abon cabai yaitu rasa teri, rebon, dan original serta satu varian produk bubuk cabai.

\section{Ucapan Terima Kasih}

Ucapan terima kasih disampaikan kepada Lembaga Penelitian dan Pengabdian kepada Masyarakat (LPPM) Universitas Lampung yang telah mendanai kegiatan ini melalui Skema Unggulan tahun 2019.

\section{Daftar Pustaka}

Buckle, K.A. 1987. Ilmu Pangan. Universitas Indonesia Press, Jakarta

Cenadi, C.H. 2000. Peranan desain kemasan dalam dunia pemasaran. Nirmana 2(1): 92-103. http://puslit2.petra.ac.id/ejournal/i nd e x.ph p/ $\mathrm{dkv/article/viewFile/16056/16048.}$ Diakses tanggal 12 Mei 2017.

Direktorat Jenderal Pengolahan dan Pemasaran Hasil Pertanian. 2009. Standar Prosedur Operasional Pengolahan Cabai. Departemen Pertanian. Jakarta.

Setiadi. 1999. Bertanam Cabai. Penebar Swadaya. Jakarta.

Sujatha, W. dan N.W. Wisaniyasa. 2007. Fisiologi dan Teknologi Pasca Panen (Buah dan Sayur). Udayana University Press. Bali. 